\title{
Трубный глас в будущее
}

В статье рассказывается о создателях первой в мире промышленной технологии производства одностенных углеродных нанотрубок (SWCNT). Нанотрубки, являющиеся универсальным аддитивом, способны кардинально менять характеристики различных материалов, в десятки раз увеличивая их прочность и долговечность, но до недавнего времени не существовало надежного и экономичного способа производить их в промышленных масштабах. Новосибирский ученый и красноярский предприниматель смогли решить эту проблему, основав стартап, который сегодня занимает 90\% мирового рынка SWCNT.

Ключевые слова: углеродные нанотрубки, Ю. Коропачинский, М. Предтеченский, OCSiAL, стартап

Как показывает опыт работы мировых венчурных фондов, более $70 \%$ их вложений оказываются провальными, зато отдельные «звезды» дают такую прибыль, которая перекрывает эти убытки и обеспечивает положительную рентабельность фонду в целом. В России, где венчурное предпринимательство появилось относительно недавно, а количество успешных стартапов исчисляется единицами, вряд ли можно говорить о какой-то статистике. Зато встречаются очень интересные кейсы. «ЭКО» предлагает вниманию читателей историю компании OCSiAL, которая первой в мире наладила промышленное производство одностенных углеродных нанотрубок (SWCNT) и фактически создала их коммерческий рынок.

\section{Инвесторы}

Это не вполне типичный случай, когда инициаторами проекта стали инвесторы. Команда инвесторов подобралась из представителей трех крупнейших научно-промышленных центров Сибири. Юрий Коропачинский, выпускник физфака Новосибирского госуниверситета, в 1994 г. вместе с братьями Вадимом и Олегом Кирилловыми (последний на тот момент возглавлял «Енисейлесинвест») создал в Красноярске финансово-промышленную группу «Стромкомбанк», из которой позже вырос «Сибмашхолдинг», а тот в свою очередь в начале 2000-х влился в «Агромашхолдинг», имеющий активы в разных регионах РФ. Выпускник Томского госуниверситета кандидат экономических наук Юрий Зельвенский возглавляет ООО «Бакчарская сталь», ООО «Томскинтелинвест». В 2004 г. Ю. Коропачинский и О. Кириллов продали свою долю в «Агромашхолдинге» группе С. Генералова и на вырученные 
средства создали инвестиционную группу компаний SM.group, которая начала активно входить в самые разнообразные сферы и даже страны - от Новой Зеландии и Австралии до Австрии, Тайланда и Люксембурга [1].

«Мы занимались бизнесом с 1991 г., имели серьезные активы в банковской сфере, владели долей в УРСА-банке (сейчас это МДМ Банк), в сельскохозяйственном машиностроении и лесопромышленности. На наших заводах работало около 35 тыс. человек. Все вроде было хорошо, но мы просто устали управлять предприятиями с огромным количеством людей, к тому же во всех этих сферах мало что меняется со временем, это скучно», - вспоминает Ю. Коропачинский [2].

Большую часть денег SM.group вкладывает в консервативные инструменты вроде девелопмента, а часть отцы-основатели решили инвестировать в высокотехнологичный бизнес. Идеи и людей было решено искать на малой родине. Заручившись согласием Президиума СО РАН, Ю. Коропачинский и его команда с 2006 г. по 2009 г. проанализировали результаты 23 институтов новосибирского Академгородка, Томска, Красноярска и Иркутска. Их интересовали области, в которых они считали себя компетентными: физика, химия, биология. Поскольку в компании не было программистов и математиков, IT-сектор отмели сразу. Основной круг поисков - новые материалы, наноэлектроника, приборостроение, биотехнологии, фармакология.

«Исследовали научно-техническую осуществимость идей, их уникальность, проверяли авторство, пытались оценить будущий рынок. Понятно, что если ты создаешь и запускаешь в производство что-то уникальное, что никто, кроме тебя, не производил, - то рынка для этого продукта еще нет. Но при этом нужно представлять, каким он будет и есть ли он вообще, - рассказывает предприниматель. - Ключевой момент в венчурном инновационном бизнесе - не найти идею, а придумать продукт. А потом запустить его в массовое производство и продать» [2].

За три года команда подвергла анализу более 1500 идей, 85\% которых были родом из Новосибирска, остальные представляли ученые из Томска и Красноярска. Из них были выделены 364 проекта, в которые инвестировали небольшие деньги, чтобы протестировать их на необходимые инвестиции, потенциальный рынок. В итоге 12 наиболее перспективных проектов были преобразованы в компании и профинансированы. Этот этап занял у SM.group четыре года, объем финансировании составил 2 млн долл. [3]

Через некоторое время пришло понимание, что просто так выйти из стадии венчурных инвестиций не удастся. Традиционно во всем мире компанию на разных этапах ее жизнедеятельности сопровождают разные инвесторы (от венчурных предпринимателей до пенсионных фондов и банков), которые на определенном этапе выходят из проекта, перепродавая свои права инвесторам следующего уровня. В России, как правило, венчурному инвестору приходится самостоятельно вести компанию до статуса «взрослой»-до продажи продукта на рынке и получения прибыли. Это - задача принципиально другого масштаба. Одно дело создать команду, дать первый толчок и продать, например, через три года, и совсем другое - в течение 10-15 лет масштабировать производство, шлифовать менеджмент.

Ю. Коропачинский: «Самое сложное - когда вы уже производите продукт, а продаж еще нет, так как нет рынка, его еще только предстоит создать. Это и есть настоящая "пустыня смерти“ для технологического предпринимателя. На этапе перехода к производству нужно менять весь менеджмент или привлекать в проект новых членов команды, способных вывести продукт на рынок. До этого момента они в команде просто не нужны, а теперь без них не обойтись. Проект должен пройти несколько стадий: как "гусеница - куколка - бабочка", и на каждой из стадий нужны управленцы разного профиля. Именно на этапе перехода к производству и продажам очень многие проекты погибают» [2].

И тут венчурный предприниматель познакомился с ученым.

\section{Ученый}

Михаил Предтеченский - доктор физико-математических наук (1994), специалист в области механики, теплофизики, энергетики, заведующий отделом физики молекулярных структур Института теплофизики (ИТ) им. С. С. Кутателадзе СО РАН, директор Международного научного центра по теплофизике и энергетике при ИТ СО РАН, с 2016 г. - академик РАН, с 2017 г. - заведующий кафедрой нанокомпозитных материалов НГУ.

С 1990-х годов активно занимался прикладной наукой и высокотехнологичным бизнесом. Тогда это направление стало для 
Института теплофизики одним из основных источников внебюджетного финансирования. Так, для американской Air Products (ведущий мировой производитель промышленных газов) им был создан уникальный прибор для сверхскоростной пайки микроэлектронных устройств. Продажа лицензии принесла институту 600 тыс. долл. и понимание правильного подхода к работе с потенциальными заказчиками. «Долгое время я в основном занимался тем, что делал многочисленные и крайне непродуктивные попытки как-то продать созданные нами за долгие годы научные разработки, - вспоминает М. Предтеченский.- После этой истории я понял, что оптимальный путь - не просто предлагать что-то “самодельное”, а применять наши знания для решения конкретных, коммерчески востребованных задач. То есть работать на перспективный заказ» [4]. Так, для Air Products были созданы новые плазмохимические технологии получения озона и водорода, а параллельно спроектирован принципиально новый тип плазмотрона.

Под эгидой специально созданного в 1997 г. при ИТ СО РАН Международного научного центра по теплофизике и энергетике, помимо Air Products, было налажено также эффективное научнотехническое сотрудничество с Hewlett-Packard, Samsung, другими зарубежными и российскими компаниями. Нашлись и партнеры, готовые массово производить оборудование, разработанное институтом. Например, Бийский котельный завод и компания «Энергия», выросшая из лаборатории ИТ, производят топливные насосы, которые поставляются не только в российские города, но и в Литву, Казахстан [4].

По воспоминаниям М. Предтеченского, он и его коллеги были в курсе основных достижений в области углеродных нанотрубок, но долгое время не понимали, как их можно использовать. Лишь осенью 2009 г., побывав на выставке «Роснанотех», ученый увидел реальные примеры их применения для получения новых материалов с уникальными свойствами. И тогда его отношение к теме резко изменилось. «Мне стало ясно, что если удастся существенно уменьшить стоимость нанотрубок, то они будут иметь реальную коммерческую ценность. Возникла идея использовать для получения "дешевых“ нанотрубок одну из наших разработок, а именно плазмохимический реактор с жидкими электродами» [5].
Знакомство ученого с Ю. Коропачинским оказалось как нельзя кстати. «Он сразу оценил масштаб и коммерческие перспективы этого направления, и мы начали обсуждать, как вместе продолжить работу по созданию и коммерциализации технологии... Это и был момент старта проекта». Уже в феврале 2010 г. Ю. Коропачинский вместе с О. Кирилловым, Ю. Зельвенским и M. Предтеченским создали компанию OCSiAL. При этом так удачно совпало, что уже с момента старта сформировалась команда, обладающая полным набором компетенций как в научнотехнической области, так и в сфере бизнеса.

Bсе остальные проекты SM.group в сфере высоких технологий было решено закрыть.

\section{Технология}

Углеродные нанотрубки (CNT) - это цилиндрические структуры диаметром от одного до нескольких десятков нанометров и длиной от нескольких микронов до нескольких сантиметров. В зависимости от количества «стенок» различают нанотрубки одностенные (single wall CNT - атомы расположены в один слой) и многостенные (multi wall CNT - в несколько слоев).

Упоминания о наблюдении различных структур углеродных нанотрубок встречаются в научной литературе с 1950-х годов, но настоящий бум в их исследовании начался в 1990-х, после вручения Нобелевской премии группе американских химиков за открытие фуллерена ${ }^{1}$. Оказалось, что нанотрубки обладают совершенно уникальными характеристиками: их электро- и теплопроводность в несколько раз выше, чем у меди, они в сто раз прочнее стали, при этом обладают экстремальной химической и температурной стойкостью, но главное - это практически универсальная добавка (аддитив), способная передавать свои замечательные свойства в другие материалы-реципиенты - металлы, пластики и бетоны, существенно меняя и расширяя их функциональные характеристики.

«CNT уже сейчас активно используются в качестве армирующей добавки в широком спектре материалов, где они выполняют роль, сходную с той, что играет стальная арматура в бетоне, -

${ }^{1}$ Фуллерен-молекулярное соединение атомов углерода, состоящее из правильных пяти- и шестиугольных граней, складывающихся в однослойную сферическую или эллипсоидную конструкцию. 
рассказывает М. Предтеченский. - Добавка одного процента CNT в алюминий позволяет получать материал со свойствами, близкими к стали; некоторые детали в автомобилях уже делают из такого материала. Мы вводим CNT в сотых долях процента от общего объема материала в различные пластики, и это не только обеспечивает их электропроводность, но и улучшает механические свойства... Уже сейчас на рынке продаются спортивные товары из таких композитов: велосипеды, горнолыжный инвентарь, клюшки, яхты, то есть те товары, где сочетание прочности и веса имеет принципиальное значение. Опыты с добавками долей процента углеродных нанотрубок в бетон показывают, что они увеличивают его прочность в полтора раза, а пенобетона - вдвое. Благодаря разнообразию уникальных свойств нанотрубок, ученые и инженеры уже предложили тысячи самых различных вариантов приложений этого материала в электронике, биотехнологии, материаловедении и других областях. Мы насчитали 16 тыс. патентов на применение CNT, зарегистрированных всего за последние несколько лет, причем количество патентов стремительно нарастает. Это говорит о высокой готовности производителей материалов использовать CNT» [5].

Однако до недавнего времени существовало промышленное производство лишь многостенных нанотрубок, удельные характеристики которых в расчете на единицу массы на порядок хуже, чем у более легких одностенных. «Многостенная трубка - это трубка, ”свернутая“" из графита, - объясняет Ю. Коропачинский, а одностенная - из графена ${ }^{2} .$. Между ними такая же разница, как между алмазом и каменным углем, хотя и то и другое состоит из углерода» [3].

Самый распространенный на сегодня способ получения CNT это так называемая парофазная эпитаксия - метод каталитического осаждения из газовой фазы. Суть его в том, что наночастица катализатора (например, железа) помещается в газовую среду, содержащую углеводород с температурой около тысячи градусов, и это приводит к разложению углеводорода с выделением атомов углерода, которые оседают на поверхности инертной подложки. Этот метод позволяет выращивать относительно дешевые CNT, цена

\footnotetext{
${ }^{2}$ Графит - модификация углерода, в которой атомные кристаллические решетки выстраиваются послойно, графен-модификация углерода толщиной в один атом.
}

которых приближается к ста долларам за килограмм, но - только многостенные и, мягко говоря, не слишком хорошего качества.

Дело в том, что многостенные CNT представляют собой клубки из туго переплетенных трубок размером около миллиметра, которые для получения более качественного материала надо еще «распутать», что очень сложно и дорого. А в спутанном виде эти трубки не дают нужного эффекта, поэтому берут их неохотно. Так что ряд западных концернов, вложивших немалые средства в развитие этой технологии, были вынуждены свернуть работы и отказаться от расширения производства [6].

Новосибирские же ученые нацелились на создание коммерчески приемлемой технологии синтеза именно одностенных углеродных нанотрубок (SWCNT), которые демонстрируют рекордную прочность и электропроводность и при этом не агломерированы, а раздельны. Для этого М. Предтеченский решил использовать разработанный им ранее плазмотрон с жидкими электродами.

«Основное преимущество нашего реактора в том, что в нем в качестве электродов дугового разряда вместо традиционных жаростойких твердых материалов используется расплав металла, - объясняет ученый.

Это позволило решить основную проблему дуговых плазмотронов - проблему ресурса электродов, которая ограничивает время непрерывной работы и мощности дугового разряда, и снять ограничения на состав газовой атмосферы, в которой горит разряд... Такая машина позволяет существенно расширить возможности плазмохимических технологий» [5]. Пригодилась она и для технологии получения графеновых нанотрубок.

Однако прежде чем получить первую промышленную партию SWCNT, компании пришлось построить 11 прототипов, потратив на это три года и 20 млн долл. А в 2012 г. проект заинтересовал корпорацию «Роснано», которая за 20 млн долл. стала обладательницей примерно 20\% активов OCSiAL. По словам Ю. Коропачинского, это был вопрос не только и не столько денег, сколько доступа к организационным ресурсам корпорации. «Масштаб проекта такой, что на определенном этапе все равно потребуются инвесторы, - говорит предприниматель. - Когда ты строишь компанию на свои деньги, получаешь семейную компанию. В семейную компанию не приходят инвесторы, в ней 
по-другому устроены управление, система принятия решений, требования к менеджменту. Чтобы компания стала публичной а мир захватывают только публичные компании, - ее надо строить с самого начала по-другому. И с самого начала научиться учитывать мнение внешнего инвестора. "Роснано“ в этом плане идеальный вариант» [3].

Корпорация «Роснано» провела комплексную научно-техническую и бизнес-экспертизу, результаты которой еще больше укрепили уверенность в правильности выбранного направления. Именно деньги госкорпорации помогли достроить первый промышленный реактор «Графетрон-1.0», запуск которого в 2013 г. обвалил мировые цены на SWCNT в 50-100 раз и обеспечил компании OCSiAL 90\% мирового рынка.

\section{Жизнь в рынке}

В 2015 г. компания выпустила 1250 кг SWCNT под торговым наименованием TUBALL. В 2016 г. - около 4 т, планы на этот год - от 7 т до 10 т. И уже полным ходом идет монтаж второй установки - «Графетрон-50» мощностью 50 т - в расчете на будущий рост мирового рынка. Еще несколько лет назад его объем оценивался в 10 т в год, но с каждым годом потенциал существенно возрастает. Если еще два года назад OCSiAL оценивала его в 145 тыс. т, то сейчас - более чем в 500 тыс. Это объясняется тем, что сферы применения продукта постоянно расширяются.

«Я думаю, что коммерческих продаж до нашего появления не было нигде и никогда. Шли небольшие партии для исследовательских целей. Покупали, как кокаин, граммами», - рассказывает Ю. Коропачинский [3]. - Наша цена 2000 долл./кг - это стоимость бутылки хорошего французского коньяка, так что мы фактически открыли дорогу массовому использованию аддитивов для кардинального изменения свойств всех известных материалов - металлов, пластиков, полимеров, резин, антикоррозийных красок, литий-ионных батарей...» [2].

В самом начале OCSiAL рассчитывал главным образом на рынок литий-ионных батарей, углепластиковые композиты и шинную промышленность - те области, где ранее применялись другие формы углерода. Но новые области применения появляются прямо на глазах. Совсем недавно профессор Орбах из израильского университета Бар-Илана спас почти целую от- расль, разработав технологию существенного увеличения ресурса кислотно-свинцовых аккумуляторов за счет SWCNT. Иначе большинство существующих аккумуляторных заводов пришлось бы закрыть из-за изменившихся условий к техрегламенту производства автомобилей [3]. И подобных примеров сотни.

Тем не менее нельзя сказать, что продвижение принципиально нового продукта далось легко. Из-за отсутствия рынка CNT у потенциальных промышленных потребителей не было ни знаний, ни опыта, ни технологий добавления углеродных нанотрубок в материалы, а зачастую - не было и простого желания вводить новшества, которые еще непонятно как монетизировать.

Для начала предприняли рекламный ход: бесплатно разослали образцы научно-производственным департаментам сотен производственных компаний. Затем пришли к выводу, что нужно продавать не столько продукт как таковой, сколько готовое технологическое решение. Поэтому в компании выбрали ряд перспективных применений CNT и начали разрабатывать соответствующие технологии производства продуктов. При этом ориентировались на рынки, где можно быстро создать истории технологического успеха либо наиболее очевидно могут проявиться свойства наномодифицированных материалов. В частности, это материалы для производства электродов для аккумуляторов, различные композиты, пластики, резины [6].

Под это направление компания создала уникальный центр прототипирования, оснащенный современным лабораторным и промышленным оборудованием. Здесь четыре десятка человек постоянно занимаются разработкой и совершенствованием промышленных технологий аддитирования нанотрубок.

Как, например, получилось, что сегодня 80\% антиэлектростатических наливных полов в России производятся из композитов с добавкой SWCNT? Bce просто: специалисты OCSiAL сами изучили свойства этих полов, создали конечную технологию их изготовления, поставляли партнерам образцы, согласовывали с ними технические регламенты и в итоге эти регламенты безвозмездно им передали. В результате, если раньше полы наливались в три слоя, то теперь - в два при лучших характеристиках, а общая себестоимость работ снизилась [6].

В компании разработали и серию суспензий - концентрированных составов на основе широко распространенных 
промышленных растворителей, с которыми партнерам намного привычнее и легче работать самостоятельно, чем с «порошком».

Налаживаются и партнерские отношения. Lanxess, Duksan, Union Chemicals, Evermore, Latern - крупнейшие компании на рынке химикатов и реагентов уже сегодня производят и реализуют по технологии OCSiAL SWCNT-содержащие концентраты. Самый крупный контракт на поставку 1,7 т порошка для производства собственных концентратов подписала Union Chemicals [6].

Для стимулирования развития рынка OCSiAL организует ежегодный Съезд представителей индустрии наномодифицированных материалов, на котором собираются сотни высокотехнологичных компаний, активно применяющих решения на основе нанотрубок.

«Пока лидеры продаж у нас на азиатских рынках - это Китай, Южная Корея, Малайзия. Там привыкли действовать активно»,рассказывает директор OCSiAL по продажам в России и СНГ А. Зимняков [7]. Европа слишком ревностно защищает свои рынки, выстраивая огромное количество сертификационных барьеров, поэтому более-менее активные продажи в ЕС начались лишь в 2016 г. - после получения сертификата REACH, регламентирующего производство и оборот химических веществ. Что касается российского рынка, в компании отмечают достаточно активный интерес к своей продукции со стороны производителей, однако, существуют проблемы, которые мешают продвижению углеродных нанотрубок. «Прежде всего за постсоветский период мы очень сильно потеряли в технологиях получения конечных качественных продуктов. Мы производим базовые материалы, в большом объеме их экспортируем. Однако при этом импортируется все, что связано, например, с дорогими высококачественными силиконами. Таким образом, наши потребители в этой сфере находятся за рубежом», - говорит А. Зимняков.

\section{Работа на перспективу}

Сейчас офисы компании работают в России, Люксембурге, США, Корее, Китае, Гонконге и Индии. Практически вся производимая компанией продукция расписана - в основном под зарубежные контракты, а уже в ближайшие два-три года в OCSiAL ждут повышения спроса на их продукцию еще на порядок за счет запуска по всему миру промышленного производства различных материалов с TUBALL.

«Пока кроме нас одностенные углеродные нанотрубки в промышленных масштабах никто в мире не производит... Этот мировой "пирог“ целиком и полностью принадлежит нам, рассуждает А. Зимняков. Но мы не питаем иллюзий, что такая ситуация будет продолжаться бесконечно. Мы считаем, что у нас есть 4-5 лет, и рынок воспроизведет эту технологию. И на тот момент наша задача, с одной стороны, научиться делать концентраты значительно лучше, чем потенциальные конкуренты, а с другой - снизить на порядок стоимость материала» [7].

Поэтому технология постоянно совершенствуется. «Безусловно, принципиальное значение для успешного продвижения проекта имеет то обстоятельство, что мы находимся в новосибирском Академгородке, где сконцентрированы институты, представляющие практически все научные направления, признает М. Предтеченский. - Это исключительное место для проведения комплексных исследований, для этого он и был создан когда-то. Мы используем эту возможность сейчас, так как наш проект создает, по сути, платформенную технологию, очень сложную, комплексную, и требует самых разных компетенций. Необходимо понимание сложных процессов роста наноструктур, процессов их введения в различные материалы и устройства; надо уметь исследовать самые разные свойства полученных материалов... Мы получили ряд принципиальных научно-технических и технологических достижений в области синтеза углеродных наноструктур, создания прототипов конечных суперпродуктов (в первую очередь - новых композитных материалов и материалов для электрохимических устройств хранения энергии)» [4].

Со временем OCSiAL планирует стать потребителем собственного сырья, создавая новые композиты, в которых нанотрубки будут составлять значительную долю. Так, в компании разработали технологию производства «бумаги», на 90\% состоящей из нанотрубок. Этот сверхлегкий, проводящий и износостойкий материал в несколько раз прочнее и легче алюминия и меди и при этом близок к ним по электрической проводимости. Его уже можно производить в промышленных масштабах, например, для авиакосмической отрасли. За счет замены медной экранирующей 
оплетки в кабеле на легкую ленту из такой «бумаги» вес кабеля можно облегчить на $15-75 \%$ [6].

С работой на перспективу тесно связан «кадровый вопрос», с которым столкнулась бурно растущая компания. «Научно-исследовательские лаборатории компании расположены на территории Академпарка, в 10 минутах пешком от НГУ и, казалось, не должны испытывать дефицита молодых специалистов, - говорит ведущий научный сотрудник OCSiAL A. Хасин. - Однако на практике найти молодого сотрудника с квалификацией, позволяющей проводить исследования в области нанокомпозитных материалов с одномерными наноаддитивами, очень непросто. Выпускникам физического факультета НГУ недостаёт для этого специальных знаний в области физической химии дисперсных систем, электрохимии, химической технологии, материаловедения. Выпускники факультета естественных наук испытывают недостаток знаний по некоторым физическим дисциплинам. Поэтому возникла идея создания новой магистерской программы, которая готовила бы специалистов в области получения, исследования свойств и применения нанокомпозитных материалов. Такие специалисты будут востребованы не только группой компаний OCSiAL, но и институтами РАН, научными центрами, инжиниринговыми и производственными компаниями, разрабатывающими и производящими нанокомпозитные материалы с самыми различными наноаддитивами: нанотрубками и волокнами, углеродными, полимерными и керамическими».

По словам А. Хасина, междисциплинарность такой программы обучения побудила организовать новую кафедру вне какого-либо факультета. Новая магистерская программа готовит и физиков, обучающихся в магистратуре физического факультета, и химиков, обучающихся на факультете естественных наук (при этом пришлось сделать две модификации программы подготовки - соответственно для физиков и химиков). Учебные курсы разработаны при участии ведущих сотрудников OCSiAL, Академпарка, институтов СО РАН. Они подготовили и сегодня читают курсы по физической химии композиционных материалов, наноуглеродным материалам и физическим методам их исследования, основам химической технологии в приложении к процессам получения дисперсий одномерных наноаддитивов, физической химии электродных композиционных материалов и др.

По словам Ю. Коропачинского, в 2018 г. компания планирует получить прибыль, продав 50 т нанотрубок на сумму не менее 75 млн долл. EBITDA при этом составит 70\%, что выше, чем у самого прибыльного продукта в мире - Apple iPhone (46\%) [2]. А это доказывает, что инновации в России возможны - при правильном подходе, огромном упорстве и некоторой доле удачи.

Но из общего ряда инноваторов отцов-основателей компании OCSiAL выделяют не только деловые качества, но и некий прогрессистский пафос, побуждающий их не сдаваться и не опускать руки в самые тяжелые времена. Здесь всерьез считают, что промышленное производство одностенных углеродных трубок-это признак начинающейся четвертой промышленной революции, которую в компании называют вступлением в «Карбоновый век». Его главный признак - появление принципиально новых базовых материалов на основе графена, которые не только позволяют добиться существенной экономии материальных и энергетических ресурсов, но и дают толчок развитию новых технологий. А с верой в такую миссию любое дело спорится.

\section{Литература}

1. Деловой квартал-Красноярск. URL: http://krasnoyarsk.dk.ru/news/ yurij-koropachinskij-lovec-dush-236579984

2. Ключевой момент в инновационном бизнесе - придумать продукт // Известия. - 2016. - 27 дек. URL: https://iz.ru/news/654749

3. Огонь, вода и нанотрубки // Популярная механика. - 2017. - № 1. URL: https://www.popmech.ru/science/317022-russkaya-tekhnologiyagrafenovye-nanotrubki/ (дата обращения: 01.10.2017).

4. Акулы академического бизнеса // Эксперт. - 2004. - № 16. URL: https://studopedia.ru/7_42573_avtonomnaya-nekommercheskayaorganizatsiya.html

5. Нанотрубный выход человечества // Эксперт. - 2013. - № 11. URL: http://novosibirsk. bezformata.ru/listnews/nanotrubnij-vihodchelovechestva/10303915/

6. Миллиард за одну стенку // Стимул. Журнал об инновациях в России URL: https://stimul.online/articles/innovatsii/milliard-za-odnu-stenku/ 7. Будущее вещей // Нефтехимия РФ. - 2017. - № 2. URL: http:// neftehimia-journal.ru/made_in_russia/budushchee-veshchey/

Материал подготовила кор. «ЭКО» Э.Ш. Веселова 